\title{
Genomic testing interacts with reproductive surplus in reducing genetic lag and increasing economic net return
}

\author{
L. Hjortø, ${ }^{* 1}$ J. F. Ettema, $\ddagger$ M. Kargo, ${ }^{\star} \S$ and A. C. Sørensen§ \\ ${ }^{*}$ Knowledge Centre for Agriculture, Agro Food Park 15, 8200 Aarhus N, Denmark \\ †SimHerd A/S, Agro Business Park, Niels Pedersens Alle 2, 8830 Tjele, Denmark \\ łDepartment of Animal Science, and \\ $\S$ Department of Molecular Biology and Genetics, Center for Quantitative Genetics and Genomics, Aarhus University, \\ PO Box 50, 8830 Tjele, Denmark
}

\begin{abstract}
Until now, genomic information has mainly been used to improve the accuracy of genomic breeding values for breeding animals at a population level. However, we hypothesize that the use of information from genotyped females also opens up the possibility of reducing genetic lag in a dairy herd, especially if genomic tests are used in combination with sexed semen or a high management level for reproductive performance, because both factors provide the opportunity for generating a reproductive surplus in the herd. In this study, sexed semen is used in combination with beef semen to produce high-value crossbred beef calves. Thus, on average there is no surplus of and selection among replacement heifers whether to go into the herd or to be sold. In this situation, the selection opportunities arise when deciding which cows to inseminate with sexed semen, conventional semen, or beef semen. We tested the hypothesis by combining the results of 2 stochastic simulation programs, SimHerd and ADAM. SimHerd estimates the economic effect of different strategies for use of sexed semen and beef semen at 3 levels of reproductive performance in a dairy herd. Besides simulating the operational return, SimHerd also simulates the parity distribution of the dams of heifer calves. The ADAM program estimates genetic merit per year in a herd under different strategies for use of sexed semen and genomic tests. The annual net return per slot was calculated as the sum of operational return and value of genetic lag minus costs of genomic tests divided by the total number of slots. Our results showed that the use of genomic tests for decision making decreases genetic lag by as much as 0.14 genetic standard deviation units of the breeding goal and that genetic lag decreases even more (up to 0.30 genetic standard deviation units) when genomic tests are used in combination with strat-
\end{abstract}

Received May 23, 2014.

Accepted October 1, 2014.

${ }^{1}$ Corresponding author: lhb@vfl.dk egies for increasing and using a reproductive surplus. Thus, our hypothesis was supported. We also observed that genomic tests are used most efficiently to decrease genetic lag when the genomic information is used more than once in the lifetime of an animal and when as many selection decisions as possible are based on genomic information. However, all breakeven prices were lower than or equal to $€ 50$, which is the current price of low-density chip genotyping in Denmark, Finland, and Sweden, so in the vast majority of cases, it is not profitable to genotype routinely for management purposes under the present price assumptions.

Key words: dairy herd management, genomic selection, modeling, sexed semen

\section{INTRODUCTION}

Sexed semen has the potential to generate a surplus of reproduction capacity in dairy herds, because fewer pregnancies are required to produce the same number of replacement heifers. Any improvement in pregnancy rate can also result in a surplus of reproduction capacity, because more pregnancies are produced per year, and fewer replacement heifers are required, because fewer cows are culled for reproductive failure. A reproductive surplus generates opportunities for deciding which cows to breed the replacements from, so it is possible to increase the selection intensity. Hence, in combination with selection, use of sexed semen results in reduced genetic lag relative to the sire population (Ettema et al., 2011; Sørensen et al., 2011).

A reproductive surplus can be used to cull low-merit newborn heifers, to sell low-merit pregnant heifers, or to select low-merit cows for production of high-value crossbred calves sired by a beef-breed bull. In this study we assume the last strategy, in which, on average, there is no selection among replacement heifers whether to go into the herd or be sold. In this situation, the selection opportunities arise when deciding which cows to inseminate with sexed semen, conventional semen, or beef semen. The effect of inseminating with sexed 
semen, conventional semen, or beef semen on reducing genetic lag depends on the accuracy with which the animals are selected.

A genomic test involves typing a large number of genetic markers and calculating a genomically enhanced breeding value (GEBV). The accuracy of GEBV differs between breeds. But, it is always higher than the accuracy of breeding values based on parent average, so a heifer with a genomic test will have its genetic merit determined at greater precision than without a genomic test (Lund et al., 2011; Thomasen et al., 2012). Hence, a better decision whether to inseminate the heifer with sexed or conventional semen can be made.

We expect that combining the use of sexed semen and genomic tests will increase both selection intensity (i) and accuracy on selection $\left(r_{\mathrm{AI}}\right)$ and, therefore, decrease genetic lag between the populations of AI bulls and cows to breed cows. However, we also expect that the effect on genetic lag of using genomic tests will be larger at high selection intensities, because the selection intensity and the accuracy interact multiplicatively in the breeder's equation: $I=i \times r_{\mathrm{AI}} \times \sigma_{H}$, where $I$ is the genetic superiority of the selected animals and $\sigma_{H}$ is the standard deviation of the breeding goal.

We, therefore, hypothesize that the use of genomic tests for decision making decreases genetic lag within the herd and mostly so in combination with use of sexed semen or high management levels for reproductive performance. Furthermore, we estimated the breakeven price of genomic tests in different scenarios of sexed semen use and management levels for reproductive performance.

\section{MATERIALS AND METHODS}

\section{General Design of the Study}

To test the hypothesis, we examined and compared the effect of varying the management level, strategies for use of sexed semen and use of genomic tests in a simulated herd with 214 slots.

\section{Outline of Experimental Design}

In this study, the management level was only characterized by the reproductive performance of the cows and the replacement rate. The number of cows inseminated with beef semen depended on the pregnancy rate and the replacement rate. Both rates are important for the age distribution of the herd and the possibility of generating a reproductive surplus. For that reason, 3 management levels with poor, average, or good reproductive performance were considered.
Table 1. Strategies for use of sexed semen

Proportion (\%) inseminated with sexed semen

\begin{tabular}{lcc}
\cline { 2 - 3 } Strategy & Heifers & $\begin{array}{c}\text { First-parity } \\
\text { cows }\end{array}$ \\
\hline H0C0 & 0 & 0 \\
H40C0 & 40 & 0 \\
H60C0 & 60 & 0 \\
H80C0 & 80 & 0 \\
H40C20 & 40 & 20 \\
H40C40 & 40 & 40 \\
H60C20 & 60 & 20 \\
H60C40 & 60 & 40 \\
\hline
\end{tabular}

Use of sexed semen may also contribute to a reproductive surplus in the herd. For that reason, 8 different strategies with varying proportions of heifers and firstparity cows being inseminated with sexed semen were compared within each management level (Table 1).

In addition, 5 different strategies for use of genomic tests were compared within each management level and in combination with the 8 strategies for use of sexed semen. The 5 strategies for use of genomic tests were

- GT0: no use of genomic tests,

- GT25c: $25 \%$ of the heifers centered on the truncation point for use of sexed semen or on the middle, if sexed semen was not used, were genotyped,

- GT50c: $50 \%$ of the heifers centered on the truncation point for use of sexed semen or on the middle, if sexed semen was not used, were genotyped,

- GT50b: top $50 \%$ of the heifers were genotyped, and

- GT100: all heifers were genotyped.

To sum up, 8 strategies for use of sexed semen times 5 strategies for use of genomic tests were simulated for 3 different management levels.

The general assumptions made in this study were representative of Danish prices and production conditions. However, we believe that the assumptions hold true for many dairy herds in the developed countries. An average Danish dairy farm with regard to production system, production level, and management level formed the basis of the simulations.

\section{General Framework of the Simulation Models}

SimHerd IV (software from Aarhus University, Tjele, Denmark) is a mechanistic, dynamic, and stochastic dairy herd model that simulates the production and state changes of dairy cows and young stock in a herd (Østergaard et al., 2005). The state of an animal is 
defined by age, parity, lactation stage, actual milk yield, BW, culling status, reproductive status (estrus and pregnancy), SCC, disease status, and a permanent environmental component of milk yield potential. The permanent environmental component accounted for approximately 0.5 of the total variance (Kristensen et al., 2008). The prediction of the current state is made week-by-week for each cow and heifer in the herd. The state of the individual animal is updated and production and input consumption of the herd calculated.

In the current study, where output of the SimHerd model was used as input for ADAM (software from Aarhus University, Tjele, Denmark), it was essential that no genetics were taken into account by SimHerd, because all genetic progress within herd and population was modeled in ADAM.

The general software ADAM is for stochastic simulation of selective breeding schemes in livestock (Pedersen et al., 2009). The program simulates a population of animals and keeps track of genetic changes in the population under different breeding scenarios. The program can handle different population structures, genetic models, selection strategies, and mating designs. In this project, ADAM was used to calculate the effect of different strategies for use of sexed semen and genomic tests on genetic level within herd.

The economic effect of different strategies for use of sexed semen at different management levels was modeled using SimHerd. Each scenario was simulated over a 20-yr period and was replicated 1,000 times. The scenarios in SimHerd were run before the scenarios in ADAM. Within scenario, the mean parity distribution of the dams of heifer calves was an output parameter from SimHerd and was used as an input parameter in ADAM. The effect of different strategies for use of sexed semen and genomic tests at different management levels on genetic merit was modeled using ADAM, and each scenario covered a 25 -yr period and was replicated 4,000 times.

\section{SimHerd}

Cow Management. First-parity cows with a milk yield higher or lower than the parity-specific median were specified to have an AI period until 330 or 225 DIM, respectively. For older-parity cows, the AI periods were terminated at 301 and 196 DIM, respectively. The AI periods were initiated $49 \mathrm{~d}$ after calving (voluntary waiting period). A cow not pregnant after the AI period was replaced when a heifer calved and entered the herd and the cow in question was the lowest-yielding candidate for voluntary culling. The proportion of cows showing estrus after calving was set at 0.95 . The estrusdetection rate and conception rate of the cows to $\mathrm{d} 14$
Table 2. Estrus-detection rate and conception rate at d 14 after AI for healthy cows and replacement rate for 3 management levels with different reproductive performance

\begin{tabular}{lccc}
\hline $\begin{array}{l}\text { Reproductive } \\
\text { performance }\end{array}$ & $\begin{array}{c}\text { Estrus-detection } \\
\text { rate (\%) }\end{array}$ & $\begin{array}{c}\text { Conception } \\
\text { rate (\%) }\end{array}$ & $\begin{array}{c}\text { Replacement } \\
\text { rate (\%) }\end{array}$ \\
\hline Poor & 28 & 44 & 44 \\
Average & 39 & 54 & 41 \\
Good & 56 & 63 & 38 \\
\hline
\end{tabular}

after AI varied between the 3 management levels (Table 2). An additional risk of fetal death, which included early fetal death, was set at 0.13 . The parameters were set to represent the breeding strategies representative for a modern, Danish dairy farm with Holstein cattle.

Replacement rate was a result of the reproductive performance of the individual cows, disease occurrence, involuntary culling, mortality, and the availability of replacement heifers. Hence, replacement rate was not a decision variable but a result of the model. Involuntary culling was represented with a linearly declining baserisk of 0.009 in wk 1 to a risk of 0.00079 in wk 29, whereafter the weekly risk was constant at 0.00079 during the rest of the lactation. Mortality was represented with a constant, weekly base-risk of 0.00034 . Furthermore, the production diseases simulated in SimHerd increased individual risk of involuntary culling and mortality. All parameters describing the lactation-curve model in SimHerd are identical to those described by Kristensen et al. (2008).

Heifer Management. The AI period for heifers was initiated at $454 \mathrm{~d}$ and terminated at $608 \mathrm{~d}$; heifers were culled when not pregnant at this age. Conception rate of the heifers for conventional semen was set at 0.55 , and estrus-detection rate was assumed to be 0.60 . The estrus-detection rate and the conception rate of the heifers were the same across the 3 management levels. Heifers were sold in cases where no cows were selected for culling and a maximum number of 214 cows was reached. Heifers were purchased in cases where herd size reached a minimum number of 190 cows.

Simulation of Sexed Semen Scenarios. Sexed semen was used on heifers and cows or on heifers alone as described in Table 1. Selection of heifers and cows to breed with sexed semen was based on random-number drawing because no genetics is modeled in this version of SimHerd. Heifers were bred with sexed semen up to 2 times, after which they were bred with normal semen until pregnancy or their insemination period was terminated (at an age of $609 \mathrm{~d}$ ) and the heifers were culled. The proportion of the conception rate obtained with sexed semen was set at $85 \%$ (DeJarnette et al., 2007) compared with that of normal semen. Firstparity cows were also bred with sexed semen up to 2 
Table 3. Cows inseminated with beef semen expressed as a percentage of the total number of cows for 8 strategies for use of sexed semen and 2 management levels with different reproductive performance

\begin{tabular}{|c|c|c|c|c|c|c|c|c|}
\hline \multirow{2}{*}{$\begin{array}{l}\text { Reproductive } \\
\text { performance }\end{array}$} & \multicolumn{8}{|c|}{ Sexed semen scenario ${ }^{1}$} \\
\hline & $\mathrm{H} 0 \mathrm{CO}$ & $\mathrm{H} 40 \mathrm{C} 0$ & $\mathrm{H} 60 \mathrm{C} 0$ & $\mathrm{H} 80 \mathrm{CO}$ & $\mathrm{H} 40 \mathrm{C} 20$ & $\mathrm{H} 40 \mathrm{C} 40$ & $\mathrm{H} 60 \mathrm{C} 20$ & H60C40 \\
\hline Average & 0 & 17 & 25 & 32 & 21 & 25 & 29 & 32 \\
\hline Good & 28 & 38 & 43 & 48 & 41 & 44 & 46 & 49 \\
\hline
\end{tabular}

times, after which they were bred with normal semen until pregnancy or their insemination period was terminated. Culling strategies for heifers and cows were the same whether sexed semen was used or not. Within each management level and in all scenarios where sexed semen was used, beef semen was used at a proportion that resulted in the same replacement rate as the scenario without use of sexed semen. At the management level with good reproductive performance and in the scenario without use of sexed semen, $28 \%$ of all cows were bred with beef semen to obtain a replacement rate of $38 \%$ (Table 3). In the alternative scenarios within this management level, the proportion of beef semen was set by calibration in a way that resulted in the same replacement rate compared with this default scenario. Thus, the scenarios are adjusted so that on average all purebred heifer calves stayed in the herd, whereas all male calves and all crossbred heifer calves were sold. The probabilities of stillbirth and dystocia involving veterinary assistance for a female calf born from a nulliparous heifer were set at 0.04 and 0.05 , respectively. These probabilities and important risk factors concerning difficulties around birth were based on scientific literature. Risk factors included an increased stillbirth risk for bull calves [simulated with a risk ratio $(\mathbf{R R})$ of 1.2; Meyer et al., 2000], increased stillbirth risk in case of dystocia ( $\mathrm{RR}=15$; Chassagne et al., 1999), increased dystocia risk for births of bull calves (RR $=2.0$ ), and decreased dystocia risk for second or later calvings $(\mathrm{RR}=0.20$; Martinez et al., 1983).

The herd with poor reproductive performance had to purchase replacement heifers in all scenarios. For that reason, beef semen was not used and the genomic test scenarios were not modeled at the management level with poor reproductive performance.

\section{ADAM}

The simulated breeding goal included a milk-production trait and a functional trait and was the same as in Buch et al. (2012). The simulated total merit index contained the same traits as the breeding goal.

Simulation of Genomic Test Scenarios. The effect of genomic tests was simulated using pseudogenomic selection (Buch et al., 2012). This implies sampling of direct genomic breeding values with genetic correlations to the 2 traits of interest corresponding to the predefined accuracy of the genomic test of 0.71 for both traits. The direct genomic breeding value is assumed to have a heritability of 0.99 , which means that the accuracy of selection of animals with a genomic test is unaffected by relatives having a genomic test or not. The direct genomic breeding value is included in calculation of a GEBV, which also includes information from relatives on the trait of interest, so all available information is used. In each age group, half of the culled cows were randomly culled to reflect involuntary culling before decisions on selection were made.

In genomic test scenarios where some of the heifers were genotyped, heifers were ranked according to parent average GEBV, so daughters of genotyped cows had on average a higher accuracy of selection. Each year, 87 and 81 replacement heifers were potential candidates for genotyping at the management levels with average

Table 4. Number of genomic tests in the different genomic test scenarios ${ }^{1}$

\begin{tabular}{lccccc}
\hline & \multicolumn{4}{c}{ Genomic test scenario } \\
\cline { 2 - 5 } $\begin{array}{l}\text { Reproductive } \\
\text { performance }\end{array}$ & GT0 & GT25c & GT50c & GT50b & GT100 \\
\hline $\begin{array}{l}\text { Average } \\
\text { Good }\end{array}$ & 0 & 22 & 44 & 44 & 87 \\
${ }^{1}$ GT0 $=$ no use of genomic tests; GT25c $=25 \%$ of the heifers centered on the truncation point for use of sexed \\
semen or on the middle, if sexed semen was not used, were genotyped; GT50c = 50\% of the heifers centered \\
on the truncation point for use of sexed semen or on the middle, if sexed semen was not used, were genotyped; \\
GT50b = top 50\% of the heifers were genotyped; GT100 = all heifers were genotyped.
\end{tabular}



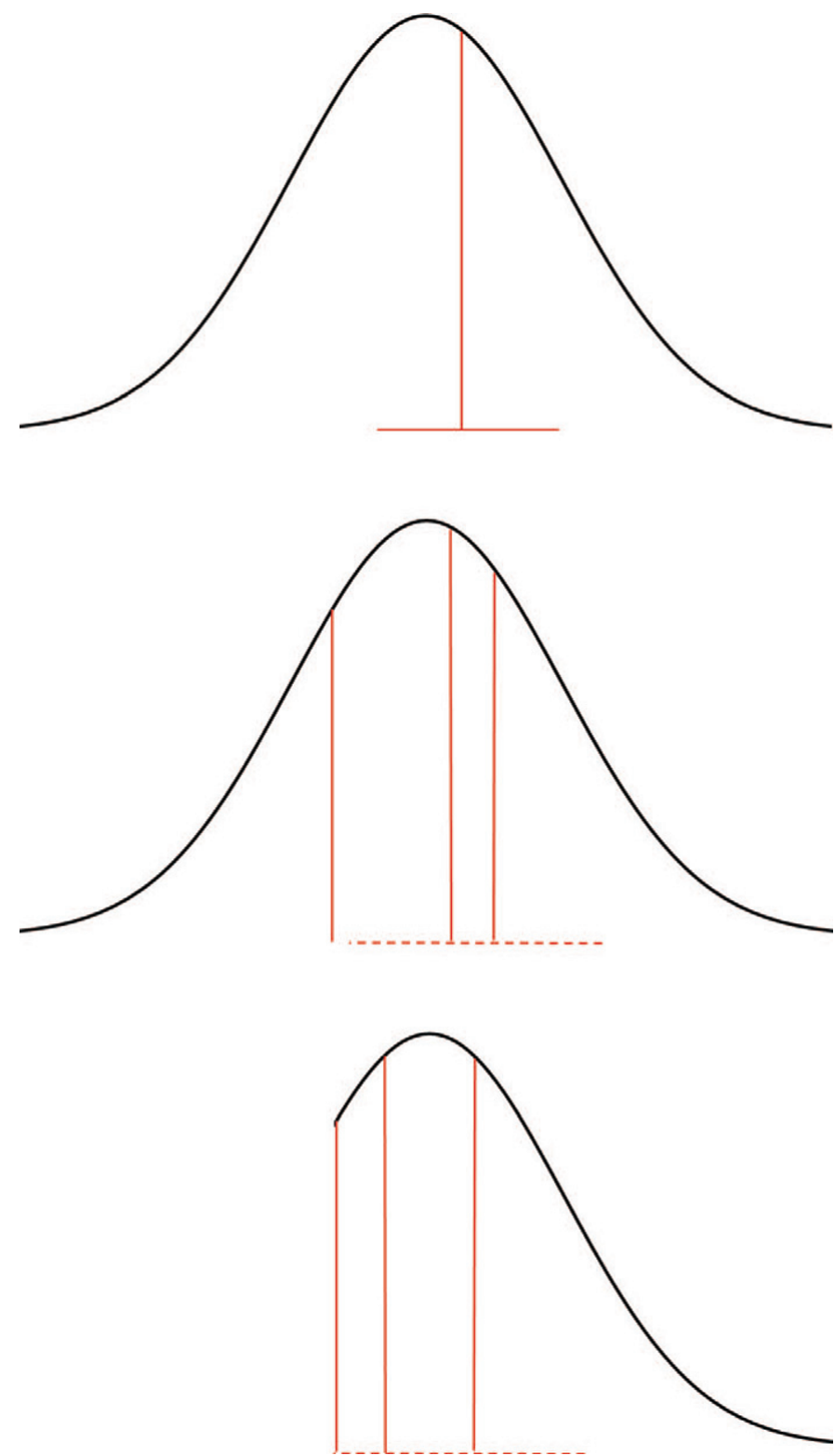

Figure 1. Illustration of selection thresholds in heifers (top), first-lactation cows (middle), and second-lactation cows (bottom) in scenario $\mathrm{H} 40 \mathrm{C} 40$ (40\% of heifers and $40 \%$ of first-parity cows were inseminated with sexed semen) under good reproduction. In heifers the 2 groups (separated by the vertical line) from the right are those inseminated with sexed semen and those inseminated with conventional semen. In first-lactation cows the 4 groups are from the right those inseminated with sexed semen, those inseminated with conventional semen, those inseminated with beef semen, and those culled. In second-lactation cows the 3 groups are from the right those inseminated with conventional semen, those inseminated with beef semen, and those culled. The horizontal line in the top figure illustrates the $50 \%$ genotyped individuals. Reranking of animals after inclusion of new information is illustrated as dashed, horizontal lines. Color version available online.

and good reproductive performance. The number of heifers genotyped varied across genomic test scenarios and levels of reproductive performance but did not de-
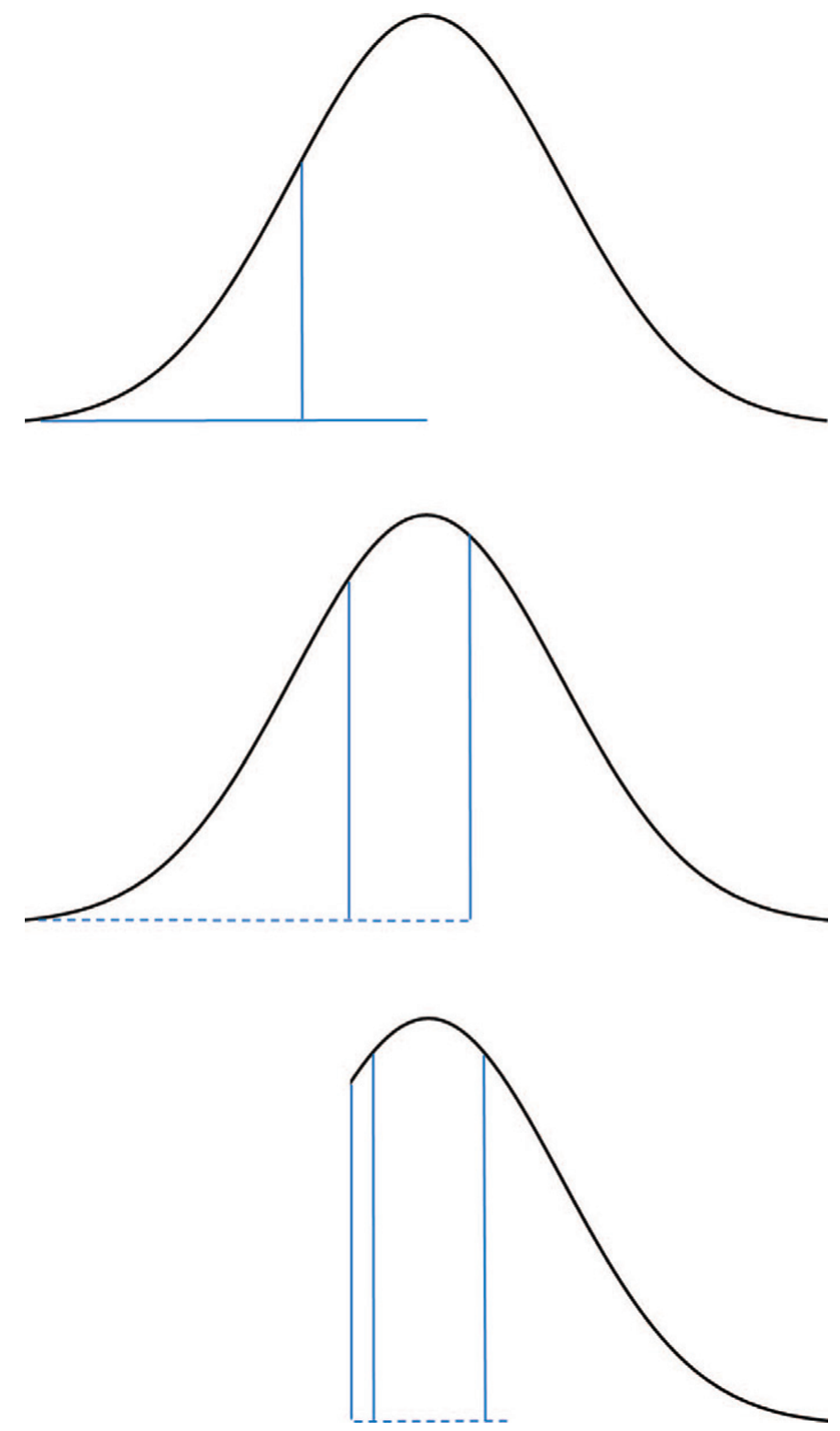

Figure 2. Illustration of selection thresholds in heifers (top), firstlactation cows (middle), and second-lactation cows (bottom) in scenario $\mathrm{H} 80 \mathrm{C} 0$ ( $80 \%$ of heifers and no cows were inseminated with sexed semen) under good reproduction. In heifers the 2 groups (separated by the vertical line) from the right are those inseminated with sexed semen and those inseminated with conventional semen. In first-lactation cows the 3 groups are from the right those inseminated with conventional semen, those inseminated with beef semen, and those culled. In second-lactation cows the 3 groups are from the right those inseminated with conventional semen, those inseminated with beef semen, and those culled. The horizontal line in the top figure illustrates the $50 \%$ genotyped individuals. Reranking of animals after inclusion of new information is illustrated as dashed, horizontal lines. Color version available online.

pend on the sexed semen strategy (Table 4). The sexed semen strategy changed the truncation point in virgin heifers and, therefore, changed the rank of the highestranked heifer that was genotyped in the 2 strategies for 
Table 5. Assumed prices and costs $(€)$ when calculating net return

\begin{tabular}{lc}
\hline Variable & $\begin{array}{c}\text { Assumed } \\
\text { price }\end{array}$ \\
\hline ECM $(€ / \mathrm{kg})$ & 0.35 \\
TMR for cows $\left(€ /\right.$ feeding unit $\left.{ }^{1}\right)$ & 0.19 \\
Conventional semen $(€ /$ dose, including service) & 24 \\
Sexed semen $(€ /$ dose, including service) & 40 \\
Beef semen $(€ /$ dose, including service) & 25 \\
Purebred bull calf $(€ / 14$-d-old calf) & 80 \\
Crossbred heifer calf $(€ /$ 14-d-old calf $)$ & 87 \\
Crossbred bull calf $(€ / 14$-d-old calf $)$ & 178 \\
Springing heifer $(€)$ & 1,340 \\
Genomic test $(€)$ & 50 \\
Genetic gain $(€ /$ yr $)$ & 33 \\
\hline
\end{tabular}

${ }^{1}$ Feeding unit is $6.7 \mathrm{MJ}$ of $\mathrm{NE}_{\mathrm{L}}$.

genotyping heifers around the truncation point. There is no truncation point if sexed semen is not used. In these scenarios, 25 or $50 \%$ of the heifers centered on the middle were genotyped.

Figures 1 and 2 illustrate how the genotypingstrategy GT50c on heifers also affected subsequent decisions taken later in the lives of the animals. In scenario H40C40 (40\% of heifers and $40 \%$ of first-parity cows were inseminated with sexed semen; Figure 1) the genotyped animals have a larger probability of remaining in the herd, allowing the genotypic information to be used repeatedly, whereas in scenario H80C0 $(80 \%$ of heifers and no cows were inseminated with sexed semen; Figure 2) a larger proportion of the genotyped animals will be culled before the second lactation.

Breeding Population. The different genomic test scenarios were applied in a single herd that did not contribute to the breeding population. The genetic trend was generated in a breeding population using 16 proven bulls for half of all inseminations and 16 young genotyped bulls for the remaining half of inseminations. The proven bulls were selected among 2 cohorts of progeny-tested bulls of 100 each, and the young genotyped bulls were selected among 1,000 genotyped bull calves. The numbers of proven and young bulls were chosen so that the genetic trend corresponded to 0.3 standard deviation units of the breeding goal, which is the expected genetic trend in the Nordic Holstein population. In the breeding goal for Nordic Holstein, the value of one genetic standard deviation unit is $€ 111$ per cow throughout its lifetime.

\section{Data Analysis}

The most important price assumptions for the calculation of net return (NR) are shown in Table 5. The price assumptions reflect the actual Danish prices in fall 2013 except the prices of ECM and TMR for cows that are from fall 2012. This is due to some price fluctuations in 2013 that seemed unrealistic in a longer perspective.

In SimHerd, data from yr 16 to 20 were used in the analyses. Operational return (OR) was calculated as the sales income minus the variable costs for cows and additional young stock. With the exception of labor associated with treatment of diseases, labor and management costs were not included as variable expenses. Also, costs for genomic tests were not included in the calculation of OR.

In ADAM, data from yr 16 to 25 were used in the analyses. Total genetic merit was monitored annually using the average over all new born females. A standard error of the mean was calculated within each scenario. Genetic level is set to zero in the scenario HoCo (no heifers or cows were inseminated with sexed semen) and GT0 under average reproductive performance, and the genetic lag for all other scenarios are reported relative to this.

For all scenarios of practical relevance, the annual NR per slot was calculated as the sum of OR and value of genetic lag minus costs of genomic tests per year, divided by the total number of slots, i.e., 214 .

\section{RESULTS}

\section{Annual NR per Slot}

When sexed semen and genomic tests were not used, the annual NR per slot were $€ 1,611, € 1,788$, and $€ 1,798$

Table 6. Difference in annual net return per slot $(€)$ of scenarios with use of sexed semen compared with no use of sexed semen at management levels with poor, average, and good reproductive performance (no use of genomic tests)

\begin{tabular}{lccccccc}
\hline & \multicolumn{7}{c}{ Sexed semen scenario ${ }^{1}$} \\
\cline { 2 - 7 } $\begin{array}{l}\text { Reproductive } \\
\text { performance }\end{array}$ & H40C0 & H60C & H80C & H40C20 & H40C40 & H60C20 & H60C40 \\
\hline Poor & 16 & 32 & 59 & 20 & 26 & 39 & 52 \\
Average & 10 & 9 & 11 & 13 & 11 & 12 & 15 \\
Good & 8 & 8 & 8 & 9 & 9 & 11 & 11 \\
\hline${ }^{1} \mathrm{H}^{*}=$ proportion of heifers (\%) inseminated with sexed semen. $\mathrm{C}^{*}=$ proportion of cows (\%) inseminated with \\
sexed semen.
\end{tabular}


Table 7. Differences in annual net return per slot $(€)$ between scenarios with use of sexed semen or genomic tests or both and the $\mathrm{H} 0 \mathrm{C} 0$ scenario without use of genomic tests (GT0) at the management level with average reproductive performance ${ }^{1}$

\begin{tabular}{lrlllllll}
\hline \multirow{2}{*}{$\begin{array}{l}\text { Genomic } \\
\text { test }\end{array}$} & \multicolumn{7}{c}{ Sexed semen scenario $^{3}$} \\
\cline { 2 - 8 } scenario $^{2}$ & H0C0 & H40C0 & H60C0 & H80C0 & H40C20 & H40C40 & H60C20 & H60C40 \\
\hline GT0 & 0 & 10 & 9 & 11 & 13 & 11 & 12 & 15 \\
GT25c & -2 & $9(1)$ & $8(1)$ & $10(1)$ & $12(1)$ & $11(2)$ & $12(2)$ & $14(1)$ \\
GT50c & -5 & $8(3)$ & $6(2)$ & $8(2)$ & $11(3)$ & $10(4)$ & $10(3)$ & $13(3)$ \\
GT50b & -6 & $6(2)$ & $5(2)$ & $8(3)$ & $10(3)$ & $9(4)$ & $8(2)$ & $12(3)$ \\
GT100 & -12 & $1(3)$ & $0(3)$ & $2(3)$ & $4(3)$ & $4(5)$ & $5(5)$ & $7(4)$ \\
\hline
\end{tabular}

${ }^{1}$ Interactions calculated as the difference between the annual net return per slot of a given scenario and the marginal effects are given in parentheses.

${ }^{2} \mathrm{GT} 0=$ no use of genomic tests; GT25c $=25 \%$ of the heifers centered on the truncation point for use of sexed semen or on the middle, if sexed semen was not used, were genotyped; GT50c $=50 \%$ of the heifers centered on the truncation point for use of sexed semen or on the middle, if sexed semen was not used, were genotyped; GT50b $=$ top $50 \%$ of the heifers were genotyped; GT100 = all heifers were genotyped.

${ }^{3} \mathrm{H}^{*}=$ proportion of heifers (\%) inseminated with sexed semen. $\mathrm{C}^{*}=$ proportion of cows (\%) inseminated with sexed semen.

at the management levels with poor, average, and good reproductive performance.

The use of sexed semen improved annual NR per slot in all scenarios (Table 6). The difference in annual NR per slot between scenarios with and without use of sexed semen decreased as the reproductive performance of the cows improved.

The annual NR per slot decreased as the number of genotyped heifers increased (Tables 7 and 8, first column). Within each management level, the effect of genotyping $50 \%$ of the heifers centered on the truncation point on the annual NR per slot was slightly better or nonexisting compared with genotyping the best half when sexed semen was not used. The decreases in annual NR per slot when using genomic tests were smaller in scenarios with a good management level than in scenarios with an average management level.
Interactions between use of sexed semen and genomic tests are presented in brackets in Tables 7 and 8 for management levels with average and good reproductive performance, respectively. The interactions are calculated as the annual NR per slot for a given sexed semen and genomic test scenario minus the annual NR per slot for the scenario without use of sexed semen and genomic tests and the marginal effects of using sexed semen and genomic tests.

All interactions between use of sexed semen and genomic tests were positive when the reproductive performance of the cows was average (Table 7). Within each sexed semen scenario, the decrease in annual NR per slot was small when genotyping $25 \%$ of the heifers compared with genotyping a higher percentage of the heifers. The largest interaction in annual NR per slot was obtained when sexed semen was used for $40 \%$ of

Table 8. Differences in annual net return per slot $(€)$ between scenarios with use of sexed semen or genomic tests or both and the H0C0 scenario without use of genomic tests (GT0) at the management level with good reproductive performance ${ }^{1}$

\begin{tabular}{lclllllrr}
\hline \multirow{2}{*}{$\begin{array}{l}\text { Genomic } \\
\text { test } \\
\text { scenario }^{2}\end{array}$} & H0C0 & H40C0 & H60C0 & H80C0 & H40C20 & H40C40 & H60C20 & H60C40 \\
\cline { 2 - 8 } & 0 & 8 & 8 & 8 & 9 & 9 & 11 & 11 \\
GT0 & 0 & $8(0)$ & $8(0)$ & $7(-1)$ & $10(1)$ & $10(1)$ & $11(0)$ & $11(0)$ \\
GT25c & 0 & $7(1)$ & $5(-1)$ & $4(-2)$ & $10(3)$ & $10(3)$ & $9(0)$ & $9(0)$ \\
GT50c & -2 & $6(1)$ & $6(1)$ & $6(1)$ & $9(3)$ & $9(3)$ & $10(2)$ & $10(2)$ \\
GT50b & -3 & $1(0)$ & $3(2)$ & $2(1)$ & $5(3)$ & $4(2)$ & $5(1)$ & $6(2)$ \\
GT100 & -7 & $1(2)$ &
\end{tabular}

${ }^{1}$ Interactions calculated as the difference between the annual net return per slot of a given scenario and the marginal effects are given in parentheses.

${ }^{2} \mathrm{GT} 0=$ no use of genomic tests; GT25c $=25 \%$ of the heifers centered on the truncation point for use of sexed semen or on the middle, if sexed semen was not used, were genotyped; GT50c $=50 \%$ of the heifers centered on the truncation point for use of sexed semen or on the middle, if sexed semen was not used, were genotyped; $\mathrm{GT} 50 \mathrm{~b}=\mathrm{top} 50 \%$ of the heifers were genotyped; GT100 = all heifers were genotyped.

${ }^{3} \mathrm{H}^{*}=$ proportion of heifers (\%) inseminated with sexed semen. $\mathrm{C}^{*}=$ proportion of cows (\%) inseminated with sexed semen. 
Table 9. Difference in operational return per slot $(€)$ between scenarios with and without use of sexed semen at management levels with poor, average, and good reproductive performance

\begin{tabular}{|c|c|c|c|c|c|c|c|}
\hline \multirow{2}{*}{$\begin{array}{l}\text { Reproductive } \\
\text { performance }\end{array}$} & \multicolumn{7}{|c|}{ Sexed semen scenario ${ }^{1}$} \\
\hline & $\mathrm{H} 40 \mathrm{C} 0$ & $\mathrm{H} 60 \mathrm{C} 0$ & $\mathrm{H} 80 \mathrm{C} 0$ & $\mathrm{H} 40 \mathrm{C} 20$ & $\mathrm{H} 40 \mathrm{C} 40$ & H60C20 & $\mathrm{H} 60 \mathrm{C} 40$ \\
\hline Poor & 12 & 27 & 53 & 15 & 21 & 33 & 46 \\
\hline Average & 0 & -2 & -1 & 2 & -1 & -1 & 1 \\
\hline Good & -1 & -2 & -2 & -1 & -1 & 0 & -1 \\
\hline
\end{tabular}

the heifers and $40 \%$ of the cows and all heifers were genotyped.

Some of the interactions were negative when sexed semen was used for heifers only, and heifers centered on the truncation point were selected for genotyping (Table 8). Conversely, all interactions were zero or positive when sexed semen was used for both heifers and cows or when the best half or all heifers were genotyped. The interactions between use of sexed semen and genomic tests were higher at the management level with average reproductive performance than at the management level with good reproductive performance (Tables 7 and 8).

When sexed semen and genomic tests were not used, OR per slot was $€ 1,609, € 1,788$, and $€ 1,794$ at the management levels with poor, average, and good reproductive performance. The OR increased as the reproductive performance improved. The use of sexed semen had a positive effect on the OR at the management level with poor reproductive performance (Table 9 ). On the other hand, OR per slot was stable across strategies for use of sexed semen when the reproductive performance of the cows was either average or good.

In the herds with average and good reproductive performance, using sexed semen on the superior heifers is combined with using beef semen on the inferior cows. In the $\mathrm{H} 80 \mathrm{C} 0$ scenario the proportion of cows bred with beef semen is 32 and $48 \%$ in the herd with average and good reproductive performance, respectively. The number of live-born, crossbred calves is 41 in the $\mathrm{H} 80 \mathrm{C} 0$ scenario for the herd with average reproductive perfor- mance. The number of live-born, purebred bull calves is 65 compared with 105 in the $\mathrm{H} 0 \mathrm{C} 0$ scenario. In the herd with good reproductive performance, the $\mathrm{H} 80 \mathrm{C} 0$ scenario resulted in 77 live-born crossbred calves. The number of live-born purebred bull calves is 61 compared with 98 in the $\mathrm{H} 0 \mathrm{C} 0$ scenario. At the management level with good reproductive performance, beef semen was already used on $28 \%$ of the cows in the H0C0 scenario, resulting in a total of 40 live-born, crossbred calves.

\section{Reduced Genetic Lag}

The differences in genetic level between scenarios with and without use of sexed semen were smallest at the management level with poor reproductive performance and largest when the reproductive performance of the cows was average (Table 10). At the management level with good reproductive performance, the differences in genetic level between scenarios with and without use of sexed semen were intermediate because the replacement rate was low and a greater proportion of old cows result in a smaller effect of sexed semen on genetic level. Note that a large, positive difference in genetic level is the same as a small genetic lag.

The use of genomic tests had a larger effect on the genetic level when the reproductive performance of the cows was good than when it was average (Table 11). Within each management level, the difference in genetic level increased as the number of genotyped heifers increased. Furthermore, the difference in genetic level was larger when the middle $50 \%$ of the heifers were

Table 10. Difference in genetic level (genetic SD units of the breeding goal) between scenarios with and without use of sexed semen at management levels with poor, average, and good reproductive performance (no use of genomic tests)

\begin{tabular}{|c|c|c|c|c|c|c|c|}
\hline \multirow{2}{*}{$\begin{array}{l}\text { Reproductive } \\
\text { performance }\end{array}$} & \multicolumn{7}{|c|}{ Sexed semen scenario ${ }^{1}$} \\
\hline & $\mathrm{H} 40 \mathrm{C} 0$ & $\mathrm{H} 60 \mathrm{C} 0$ & $\mathrm{H} 80 \mathrm{C} 0$ & $\mathrm{H} 40 \mathrm{C} 20$ & H40C40 & H60C20 & H60C40 \\
\hline Poor & 0.059 & 0.070 & 0.082 & 0.066 & 0.070 & 0.080 & 0.094 \\
\hline Average & 0.103 & 0.129 & 0.131 & 0.121 & 0.130 & 0.146 & 0.161 \\
\hline Good & 0.104 & 0.112 & 0.118 & 0.113 & 0.121 & 0.130 & 0.140 \\
\hline
\end{tabular}


Table 11. Difference in genetic level (genetic SD units of the breeding goal) between scenarios with and without use of genomic tests at management levels with average and good reproductive performance (no use of sexed semen)

\begin{tabular}{lcccc}
\hline & \multicolumn{4}{c}{ Genomic test scenario $^{1}$} \\
\cline { 2 - 5 } $\begin{array}{l}\text { Reproductive } \\
\text { performance }\end{array}$ & GT25c & GT50c & GT50b & GT100 \\
\hline Average & 0.036 & 0.058 & 0.050 & 0.096 \\
Good & 0.056 & 0.093 & 0.081 & 0.137 \\
\hline
\end{tabular}

${ }^{1} \mathrm{GT} 25 \mathrm{c}=25 \%$ of the heifers centered on the truncation point for use of sexed semen or on the middle, if sexed semen was not used, were genotyped; GT50c $=50 \%$ of the heifers centered on the truncation point for use of sexed semen or on the middle, if sexed semen was not used, were genotyped; GT50b $=$ top $50 \%$ of the heifers were genotyped; GT100 = all heifers were genotyped.

genotyped than when the best half of the heifers was genotyped.

Interactions between use of sexed semen and genomic tests were all positive at the management level with average reproductive performance (Table 12). At the management level with good reproductive performance the interactions were smaller and even some were negative (Table 13). The negative interactions only occur for strategies of genotyping heifers centered on the truncation point (GT25c and GT50c) and only in scenarios where sexed semen is used for heifers only.

Table 14 shows breakeven prices for a genomic test within each management level. The breakeven prices are calculated so that the difference in annual NR per slot between $\mathrm{H} 0 \mathrm{CO}$ scenarios with and without use of genomic tests is zero. A higher breakeven price means that the information from genomic tests is more valuable. Within each genomic test scenario, the breakeven prices are higher at the management level with good reproductive performance than at the management level with average reproductive performance. Within each management level, the breakeven price is lower when more genomic tests are performed.
Table 15 shows breakeven prices for a genomic test within each management level. The breakeven prices are calculated so that the difference in annual NR per slot between GT100 and GT0 is zero. The large differences between breakeven prices at the management levels with average and good reproductive performances in Table 14 are lessened when sexed semen is used (Table 15), because the use of sexed semen at the management level with average reproductive performance increases the breakeven price, whereas the effect of sexed semen at the management level with good reproductive performance is smaller.

\section{DISCUSSION}

This study supported our hypothesis that the use of genomic tests for decision making decreases genetic lag within the herd, because all differences in genetic level between scenarios with and without use of genomic tests were positive when the reproductive performance of the cows was average or good (Table 11). The study also supported the hypothesis that genetic lag is decreased even more when genomic tests are used in combination with high management levels for reproductive performance or use of sexed semen. The support is demonstrated in (1) that the differences in genetic level between scenarios with and without use of genomic tests were larger when the reproductive performance of the cows was good compared with average (Table 11); and (2) that the interactions between use of sexed semen and genomic tests on genetic level are predominantly positive (Tables 12 and 13). In addition, we estimated all breakeven prices to be lower than or equal to $€ 50$ (Tables 14 and 15), which is the price assumed in this study and the current price of a low-density chip genotyping in Denmark, Finland, and Sweden. Hence, in most herds today the use of genomic tests for management purposes is not profitable, but

Table 12. Interactions between use of sexed semen and genomic tests on genetic level (genetic SD units of the breeding goal) at the management level with average reproductive performance

\begin{tabular}{lccccccc}
\hline $\begin{array}{l}\text { Genomic } \\
\text { test }\end{array}$ & \multicolumn{7}{c}{ Sexed semen scenario $^{2}$} \\
\cline { 2 - 7 } scenario $^{1}$ & H40C0 & H60C0 & H80C0 & H40C20 & H40C40 & H60C20 & H60C40 \\
\hline GT25c $^{3}$ & 0.013 & 0.012 & 0.009 & 0.012 & 0.025 & 0.018 & 0.013 \\
GT50c $^{3}$ & 0.036 & 0.024 & 0.018 & 0.032 & 0.046 & 0.036 & 0.032 \\
GT50b $^{4}$ & 0.024 & 0.023 & 0.030 & 0.035 & 0.042 & 0.027 & 0.037 \\
GT100 $^{5}$ & 0.032 & 0.029 & 0.032 & 0.034 & 0.054 & 0.052 & 0.049 \\
\hline
\end{tabular}

${ }^{1} \mathrm{GT} 25 \mathrm{c}=25 \%$ of the heifers centered on the truncation point for use of sexed semen or on the middle, if sexed semen was not used, were genotyped; GT50c $=50 \%$ of the heifers centered on the truncation point for use of sexed semen or on the middle, if sexed semen was not used, were genotyped; GT50b $=$ top $50 \%$ of the heifers were genotyped; GT100 = all heifers were genotyped.

${ }^{2} \mathrm{H}^{*}=$ proportion of heifers (\%) inseminated with sexed semen. $\mathrm{C}^{*}=$ proportion of cows (\%) inseminated with sexed semen. 
Table 13. Interactions between use of sexed semen and genomic tests on genetic level (genetic SD units of the breeding goal) at the management level with good reproductive performance

\begin{tabular}{lrrrrrrr}
\hline \multirow{2}{*}{$\begin{array}{l}\text { Genomic } \\
\text { test }\end{array}$} & \multicolumn{7}{c}{ Sexed semen scenario $^{2}$} \\
\cline { 2 - 7 } scenario $^{1}$ & H40C0 & H60C0 & H80C0 & H40C20 & H40C40 & H60C20 & H60C40 \\
\hline GT25c & -0.002 & -0.003 & -0.011 & 0.015 & 0.016 & 0.005 & -0.001 \\
GT50c & 0.012 & -0.007 & -0.024 & 0.029 & 0.033 & 0.004 & 0.003 \\
GT50b & 0.006 & 0.017 & 0.011 & 0.032 & 0.038 & 0.022 & 0.026 \\
GT100 & 0.004 & 0.019 & 0.015 & 0.031 & 0.027 & 0.016 & 0.023 \\
\hline
\end{tabular}

${ }^{1} \mathrm{GT} 25 \mathrm{c}=25 \%$ of the heifers centered on the truncation point for use of sexed semen or on the middle, if sexed semen was not used, were genotyped; GT50c $=50 \%$ of the heifers centered on the truncation point for use of sexed semen or on the middle, if sexed semen was not used, were genotyped; GT50b $=$ top $50 \%$ of the heifers were genotyped; GT100 = all heifers were genotyped.

${ }^{2} \mathrm{H}^{*}=$ proportion of heifers (\%) inseminated with sexed semen. $\mathrm{C}^{*}=$ proportion of cows $(\%)$ inseminated with sexed semen.

it will likely be an important management tool in the future (Boichard et al., 2013).

\section{Interaction Between Use of Sexed Semen and Genomic Tests}

As outlined in the introduction, we expected that the combined use of sexed semen and genomic tests decreases genetic lag because both selection intensity and accuracy on selection will increase. Our results supported this expectation. At the management level with average reproductive performance, all interactions between use of sexed semen and genomic tests on genetic level were positive, and the largest interaction was found in the H40C40 and GT100 scenario (Table 12). The interactions were generally lower when the reproductive performance of the cows was good compared with average, and some of the interactions were even negative (Table 13). The reason is likely that the marginal increase in reproductive surplus due to use of sexed semen is larger under average reproductive performance. Regardless of management level, the largest interactions were found in the scenarios where both heifers and cows were inseminated with sexed semen. The explanation is that the accurate information originating from genomic tests is used more than once in the life of an animal in these scenarios. In all GT25c and GT50c scenarios, the highest interactions were found when $40 \%$ of the heifers and $40 \%$ of the cows were inseminated with sexed semen. The reason may be that more cows around the truncation points for using sexed semen or for culling were genotyped in the H40C40 scenario. This issue is illustrated in 2 scenarios using the GT50c strategy. In H40C40, more selection decisions were taken on genotyped cows (Figure 1), whereas in $\mathrm{H} 80 \mathrm{C} 0$, many of the selection decisions were taken on cows without genomic tests (Figure 2).

The interactions between use of sexed semen and genomic tests on annual NR per slot (Tables 7 and 8) showed the same patterns as the interactions on the genetic level (Tables 12 and 13) because the annual OR was the same within each management and sexed semen scenario and across all genomic test scenarios. Therefore, the genetic lag decreases when more decisions are based on genomic test information, i.e., with increased frequency of genotyped females around the truncation points across age groups.

\section{Interaction Between Use of Sexed Semen and Management Level}

At the management level with poor reproductive performance, all differences in annual OR per slot between scenarios with and without use of sexed semen were positive (Table 9). This is because the herd with poor reproductive performance is not able to produce enough heifers and has to buy heifers every year instead. However, heifers are not bought until herd size reaches a lower limit of 190 cows. The use of sexed semen partly reduces the need to buy heifers; only 6 instead of 21 heifers need to be bought in the $\mathrm{H} 80 \mathrm{C} 0$ scenario compared with the $\mathrm{H} 0 \mathrm{C} 0$ scenario, with the effect that the average number of cow-years is 203 in the H80C0 scenario compared with 199 in

Table 14. Breakeven prices for a genomic test $(€)$ at management levels with average and good reproductive performance (no use of sexed semen)

\begin{tabular}{lcccc}
\hline & \multicolumn{4}{c}{ Genomic test scenario } \\
\cline { 2 - 5 } Reproductive \\
performance & GT25c & GT50c & GT50b & GT100 \\
\hline Average & 31.5 & 25.5 & 22.0 & 21.0 \\
Good & 50.0 & 41.5 & 36.5 & 30.5 \\
\hline
\end{tabular}

${ }^{1} \mathrm{GT} 25 \mathrm{c}=25 \%$ of the heifers centered on the truncation point for use of sexed semen or on the middle, if sexed semen was not used, were genotyped; GT50c $=50 \%$ of the heifers centered on the truncation point for use of sexed semen or on the middle, if sexed semen was not used, were genotyped; GT50b = top 50\% of the heifers were genotyped; GT100 = all heifers were genotyped. 
Table 15. Breakeven prices for a genomic test $(€)$ at management levels with average and good reproductive performance when GT100 is compared with GT0 within each strategy for use of sexed semen

\begin{tabular}{lcccccccc}
\hline & \multicolumn{7}{c}{ Sexed semen scenario } \\
\cline { 2 - 8 } $\begin{array}{l}\text { Reproductive } \\
\text { performance }\end{array}$ & H0C0 & H40C0 & H60C0 & H80C 0 & H40C20 & H40C40 & H60C20 & H60C40 \\
\hline Average & 21.0 & 28.0 & 27.5 & 28.0 & 28.5 & 33.0 & 32.5 & 32.0 \\
Good & 30.5 & 31.0 & 34.5 & 33.5 & 37.0 & 36.5 & 34.0 & 35.5 \\
\hline${ }^{1} \mathrm{H}^{*}=$ proportion of heifers (\%) inseminated with sexed semen. C* $=$ proportion of cows (\%) inseminated with \\
sexed semen.
\end{tabular}

the H0C0 scenario. Hence, using sexed semen increased the stocking rate in the herd with poor reproductive performance and therefore has a large effect on NR per slot. Also keep in mind that the management level was characterized by the reproductive performance of the cows and not the heifers. This is the reason why the largest differences were found in scenarios with use of sexed semen to heifers only and a poor management level. Conversely, all differences in annual OR per slot between scenarios with and without use of sexed semen were zero or slightly negative at the management level with good reproductive performance. The reason is that replacement rate is kept constant within each management level and therefore the income of milk and beef are approximately constant.

The use of sexed semen increases annual NR per slot (Table 6) because the genetic level is improved (Table 10). The mechanism behind this improvement is that with sexed semen, the average age of dams of replacement heifers is decreased. This reduction in age increases the genetic merit of replacement heifers, because younger animals are genetically superior due to a positive genetic trend in the population supplying the bull semen. However, the more directional selection (higher selection intensity) that occurs in sequence from heifers to older cows, the smaller the difference between the age groups of females in the herd, and the smaller benefit of recruiting replacement heifers from the young dams only. This mechanism also explains that the positive effect on genetic lag of using sexed semen is slightly smaller in herds with good reproductive performance compared with herds with average reproductive performance. The effect of using sexed semen on genetic lag is smaller at the management level with poor reproductive performance than at the management levels with average and good reproductive performance. This is due to the fact that increased use of sexed semen does not get combined with increased use of beef semen, as is the case for the other 2 management levels. Using sexed semen is necessary simply to reduce the shortage of heifers in the herd with poor reproductive performance. Furthermore, fewer female offspring are born from the genetically best cows because fewer of these cows are pregnant after 2 inseminations with sexed semen at the management level with poor reproductive performance.

\section{Effect of Genomic Tests when Sexed Semen Is Not Used}

Within all genomic test scenarios, the positive effect of using genomic tests on genetic lag was larger in the scenarios with good reproductive performance compared with average reproductive performance when sexed semen was not used (Table 11). The reason is that more replacement heifers were born from the best dams, because not all cows are needed for breeding replacement heifers in scenarios with good reproductive performance. This is illustrated by the fact that more low-ranking cows can be inseminated with beef semen (Table 3). Whether it is worthwhile to test all or part of the herd or not depends on the cost related to genomic tests. At the current price of genomic test, there is no gain in NR when sexed semen is not used.

\section{Breakeven Costs of Genomic Tests}

In most cases, the improvement of the genetic level was not large enough to offset the assumed cost of genotyping when sexed semen was not used (Tables 7 and 8 ). However, this was not the case when $25 \%$ of the heifers centered on the truncation point were genotyped and the reproductive performance of the cows was good. Weigel et al. (2012) found that it can be cost effective to genotype $50 \%$ of the heifer calves after presorting by traditional EBV if a genomic test costs $\$ 40$ or $€ 30$ and pedigree information is available. The results of our study support the results of Weigel et al. (2012) when the reproductive performance of the cows is good. Today, genotyping with $10 \mathrm{~K}$ and $54 \mathrm{~K}$ chips cost $€ 50$ and $€ 77$ per female, respectively, in Denmark, Finland, and Sweden. However, Boichard et al. (2013) predict that a genomic test will cost between $€ 30$ and $€ 45$ in the future. If the reproductive performance of the cows is good and a genomic test costs $€ 30$, then the most profitable strategy includes use of sexed semen and genomic tests. Most strategies for use of sexed 
semen to both heifers and cows are profitable if the reproductive performance is average and a genomic test costs €30. Furthermore, Pryce and Hayes (2012) argue that it is easier to profit from genotyping if the genomic information is also used for other purposes than selecting replacement heifers, e.g., parentage verification and mating plans to control inbreeding (Sun et al., 2013). The value of genotyping for selection purposes depends critically on the accuracy of GEBV. If this accuracy, e.g., in some large, cooperating Holstein populations, is higher than the assumed accuracy in this study, then the breakeven prices will be higher. If, on the other hand, the accuracy of GEBV, e.g., in smaller or more heterogeneous populations, is lower than the assumed accuracy in this study, then the breakeven prices will be lower. However, in general we expect the accuracies to increase over time. Hence, given that the price of genotyping will fall and the information content will increase, the future best practice in dairy herd management will likely include genomic testing of at least some females.

\section{Alternative Use of Reproductive Surplus}

In our study, the cows with lowest genetic merit were selected to breed with beef semen. In the analysis by Weigel et al. (2012) yearling heifers were culled based on low genomic-predicted transmitting abilities. We expect that a higher genetic progress could have been obtained in our study, in case any reproductive surplus was used as done by Weigel et al. (2012). We reason thus because it is more accurate to select the individuals themselves, based on information on Mendelian sampling terms, than to select the dams. We have not explicitly evaluated the economics of other strategies, such as culling surplus yearling heifers or surplus newborn heifer calves. We have chosen to focus on the use of reproductive surplus for production of high-value crossbred calves, because the Danish government uses subsidies to incite the production of veal.

\section{Subsidy to Beef Production}

In Europe, the production of fattening calves is subsidized by $€ 67$ per bull calf that reaches a slaughter weight of $160 \mathrm{~kg}$. The beef farmer typically includes this subsidy in the price that he pays the dairy farmer for the 14-d-old bull calves. We conducted a sensitivity analysis by subtracting the subsidy from the prices used in this study so that the price for a purebred bull calf is $€ 13$ instead of $€ 80$, the price for crossbred bull calves is $€ 111$ instead of $€ 178$, and the price for crossbred heifer calves remains $€ 87$, because beef farmers do not receive subsidy for heifer calves. Using these prices results in an OR per slot of $€ 1,755$ compared with €1,788 (-€33) for the H0C0 scenario in the herd with average reproduction. This decrease is solely due to the lower value of purebred bull calves. In the scenario where most crossbred calves are produced (H80C0), OR per slot drops from $€ 1,787$ to $€ 1,760$ (-€27); OR drops, but not as much compared with the H0C0 scenario because fewer purebred bull calves are sold in this scenario and the prices of the crossbred heifer calves were not changed. The difference between these 2 scenarios increases from -€1 to €5 per slot when $\mathrm{H} 80 \mathrm{C} 0$ is compared with $\mathrm{H} 0 \mathrm{C} 0$. For the herd with good reproduction, subtracting the $€ 67$ from the bull prices results in an increase of the difference from $-€ 2$ to $€ 3$ when comparing $\mathrm{H} 80 \mathrm{C} 0$ with $\mathrm{H} 0 \mathrm{C} 0$. Whether an elimination of this subsidy affects the bull prices as described above is uncertain. It can also be imagined that the purebred bull calf will be considered useless by the dairy farmer when the prices approach zero. A consequence could be that the bull calves get euthanized immediately after birth. This will increase the demand for crossbred calves and increase the relative value of the crossbred heifer calf. A study on market values of calf prices in a market without subsidies shows a difference between crossbred bull and heifer calves of $\$ 77$ and $\$ 93$ (€0.8:\$1, in 2003 to 2007, during which this study was performed) when the breed of the sire was Limousin or Belgian Blue, respectively (Dal Zotto et al., 2009). The difference between crossbred bull and heifer calves was $€ 91$ in the current study. Hence, the results of our study are not particularly sensitive to the assumption of subsidy or not, because the main driver in the NR is the milk production.

\section{CONCLUSIONS}

The use of genomic tests will decrease the genetic lag in a dairy herd. However, in very few cases will it be economically worthwhile to genotype routinely for management purposes at the current prices for genomic tests. The use of genomic tests is most beneficial when combined with strategies for increasing and using reproductive surplus; for example, by using sexed and beef semen. A positive interaction exists between the increased accuracy of selection from the genomic information and the increased selection intensity from the combined use of sexed semen and beef semen. Overall, genomic tests are used most efficiently to decrease genetic lag when the genomic information is used more than once in the lifetime of the animal and when as many selection decisions as possible are based on genomic information. 


\section{ACKNOWLEDGMENTS}

This research was financially supported by Promilleafgiftsfonden for Landbrug.

\section{REFERENCES}

Boichard, D., R. Dassonville, S. Mattalia, V. Ducrocq, and S. Fritz. 2013. All cows are worth to be genotyped! Page 184 in Book of Abstracts of the 64th Annual Meeting of the European Federation of Animal Science. Nantes, France. Wageningen Academic Publishers, Wageningen, the Netherlands.

Buch, L. H., M. Kargo, P. Berg, L. D. Pedersen, and A. C. Sørensen. 2012. Genomic selection strategies in dairy cattle: Strong positive interaction between use of genotypic information and intensive use of young bulls on genetic gain. J. Anim. Breed. Genet. 129:138-151.

Chassagne, M., J. Barnouin, and J. P. Chacornac. 1999. Risk factors for stillbirth in Holstein heifers under field conditions in France: A prospective survey. Theriogenology 51:1477-1488.

Dal Zotto, R., M. Penasa, M. De Marchi, M. Cassandro, N. Lopez-Villalobos, and G. Bittante. 2009. Use of crossbreeding with beef bulls in dairy herds: Effect on age, body weight, price, and market value of calves sold at livestock auctions. J. Anim. Sci. 87:3053-3059.

DeJarnette, J. M., R. L. Nebel, J. Meek, J. Wells, and C. E. Marshall. 2007. Commercial application of sex-sorted semen in Holstein heifers. J. Dairy Sci. 90(Suppl. 1):228. (Abstr.)

Ettema, J. F., S. Østergård, and M. K. Sørensen. 2011. Effect of including milk yield on evaluating the use of sexed semen and other reproduction strategies in a dairy herd. Animal 5:1887-1897.

Kristensen, E., S. Østergaard, M. A. Krogh, and C. Enevoldsen. 2008. Technical indicators of financial performance in the dairy herd. J. Dairy Sci. 91:620-631.
Lund, M. S., A. P. W. de Roos, A. G. De Vries, T. Druet, V. Ducrocq, S. Fritz, F. Guillaume, B. Guldbrandtsen, Z. Liu, R. Reents, C. Schrooten, F. Seefried, and G. Su. 2011. A common reference population from four European Holstein populations increases reliability of genomic predictions. Genet. Sel. Evol. 43:43.

Martinez, M. L., A. E. Freeman, and P. J. Berger. 1983. Factors affecting calf livability for Holsteins. J. Dairy Sci. 66:2400-2407.

Meyer, C. L., P. J. Berger, and K. J. Koehler. 2000. Interactions among factors affecting stillbirths in Holstein cattle in the United States. J. Dairy Sci. 83:2657-2663.

Østergaard, S., M. G. G. Chagunda, N. C. Friggens, T. W. Bennedsgaard, and I. C. Klaas. 2005. A stochastic model simulating pathogen-specific mastitis control in a dairy herd. J. Dairy Sci. 88:4243-4257.

Pedersen, L. D., A. C. Sørensen, M. Henryon, S. Ansari-Mahyari, and P. Berg. 2009. ADAM: A computer program to simulate selective breeding schemes for animals. Livest. Sci. 121:343-344.

Pryce, J., and B. Hayes. 2012. A review of how dairy farmers can use and profit from genomic technologies. Anim. Prod. Sci. 52:180184.

Sørensen, M. K., J. Voergård, L. D. Pedersen, P. Berg, and A. C. Sørensen. 2011. Genetic gain in dairy populations is increased using sexed semen in commercial herds. J. Anim. Breed. Genet. $128: 267-275$.

Sun, C., P. M. VanRaden, J. R. O'Connell, K. A. Weigel, and D. Gianola. 2013. Mating programs including genomic relationships and dominance effects. J. Dairy Sci. 96:8014-8023.

Thomasen, J. R., B. Guldbrandtsen, G. Su, R. F. Brøndum, and M. S. Lund. 2012. Reliabilities of genomic estimated breeding values in Danish Jersey. Animal 6:789-796.

Weigel, K. A., P. C. Hoffman, W. Herring, and T. J. Lawlor Jr. 2012 Potential gains in lifetime net merit from genomic testing of cows, heifers, and calves on commercial dairy farms. J. Dairy Sci. 95:2215-2225. 